\title{
Aplikasi Bahasa Isyarat Pengenalan Huruf Hijaiyah Bagi Penyandang Disabilitas Tuna Runggu
}

\author{
Nurul Huda \\ Fakultas Ilmu Komputer, Universitas Bina Darma \\ Jalan A. Yani no.3 Palembang \\ nurul_huda@binadarma.ac.id
}

\begin{abstract}
Abstrak---Pengenalan huruf hijaiyah tidak hanya dikenalkan kepada orang-orang yang berkehidupan normal saja tetapi juga harus dikenalkan kepada orang-orang yang memiliki kebutuhan khusus terutama bagi yang beragama Islam seperti halnya kepada para penyandang disabilitas tuna rungu. Tuna rungu merupakan seseorang yang mengalami kesulitan dalam pendengarannya, sehingga dalam berkomunikasi para penderita tuna rungu menggunakan bahasa isyarat. Saat ini masih jarang ditemui media yang dapat digunakan untuk memberikan pendidikan kepada penyandang tuna rungu dalam mengenal dan memahami huruf hijaiyah, dimana sebelumnya pernah digunakan media buku isyarat tetapi saat ini buku tersebut sangat sulit ditemukan. Permasalahan tersebut menyebabkan penyandang tuna rungu kesulitan dalam mengenal dan mempelajari huruf-huruf hijaiyah. Oleh karena itu, penelitian ini bertujuan untuk membangun sebuah aplikasi pengenalan huruf hijaiyah bagi penyandang tuna rungu agar mempermudah mereka dalam mengenal huruf-huruf hijaiyah. Penelitian ini menggunakan metode pengembangan sistem waterfall, sehingga aplikasi hasil dari penelitian ini dapat digunakan penyandang tuna rungu dalam mengenal huruf-huruf hijaiyah serta dapat membaca Al-Qur'an dengan baik dan benar.
\end{abstract}

Kata kunci-- Huruf Hijaiyah, Tuna Rungu, Waterfall

\section{PENDAHULUAN}

Penyandang tuna rungu memiliki hambatan dalam pendengaran karena memiliki hambatan tersebut maka tunarungu pun memiliki hambatan dalam berbicara sehingga mereka biasa disebut tunawicara [1]. Tuna rungu merupakan seseorang yang mengalami kesulitan dalam pendengarannya, sehingga dalam berkomunikasi para penderita tuna rungu menggunakan bahasa isyarat. Cara berkomunikasi dengan individu tersebut menggunakan bahasa isyarat, untuk abjad jari telah dipatenkan secara internasional sedangkan untuk isyarat bahasa berbeda-beda di setiap negara [2]. Permasalahan yang terjadi adalah kesulitan penyandang tuna rungu dalam mengenal dan mempelajari huruf-huruf hijaiyah, dimana sangat sulitnya menemukan bahkan tidak ditemukan lagi media pembelajaran baik itu buku maupun media elektronik yang dapat digunakan penyandang tuna rungu dalam mengenal huruf-huruf hijaiyah. Beberapa waktu yang lalu pernah diterbitkan sebuah buku isyarat yang berisikan tentang pengenalan huruf hijaiyah bagi penyandang tuna rungu, tetapi saat ini buku yang menggunakan bahasa isyarat itupun telah sulit untuk ditemukan. Bahasa isyarat yang sederhana ataupun bentuk lain perlu dipahami oleh orang normal dalam berkomunikasi sehari-hari. Salah satu kesulitan adalah bagaimana orang tuli menginformasikan bahasa isyarat yang digunakan dan dapat dipahami oleh orang yang bisa mendengar sehingga penderita tuna rungu dapat berkomunikasi, berinteraksi, bergaul, berteman, dan terjadi dialog dalam pergaulan sehari-hari [3]. Bahasa isyarat bukan hanya dibutuhkan oleh penderita tuna rungu dalam berkomunikasi sesama manusia sehari-hari dalam, tetapi juga dibutuhkan dalam mengenal dan membaca Al-qur'an, diantaranya adalah dalam mengenal huruf-huruf hijaiyah.

Pengenalan huruf hijaiyah merupakan kunci dasar mampu membaca Al-Qur'an dan Hadis. HurufHijaiyah, bagi seorang muslim, menjadi kebutuhan dasar dalam memahami kedua pedoman pokok kehidupannya. Hijaiyah atau juga sering dikenal sebagai huruf Arab itu berjumlah 29 huruf. Huruf itu kemudian merupakan bagian dari bahasa Arab yang menjadi bahasa pokok dalam Quran dan Hadist [4]. Dengan memanfaatkan perkembangan teknologi komputer, maka penulis akan membangun sebuah aplikasi pengenalan huruf hijaiyah yang dikhususkan bagi penyandang tuna rungu agar para penyandang disabilitas tuna rungu dapat lebih mengenal huruf-huruf hijaiyah dan diharapkan dapat membaca AlQur'an dengan baik dan benar sehingga menjadi penghafal AlQur'an karena huruf hijaiyah ini merupakan pelajaran dasar dalam pengenalan huruf-huruf dalam Al-Qur'an.

\section{TINJAUAN PUSTAKA}

\section{A. DisABILITAS}

Difabel atau disabilitas adalah istilah yang meliputi gangguan, keterbatasan aktivitas, dan pembatasan partisipasi [5]. Gangguan adalah sebuah masalah pada fungsi tubuh atau strukturnya, suatu pembatasan kegiatan adalah kesulitan yang dihadapi oleh individu dalam melaksanakan tugas atau tindakan, sedangkan pembatasan partisipasi merupakan masalah yang dialami oleh individu dalam keterlibatan dalam situasi kehidupan. Jadi disabilitas adalah sebuah fenomena 
kompleks, yang mencerminkan interaksi antara ciri dari tubuh seseorang dan ciri dari masyarakat tempat dia tinggal.

Penyandang cacat adalah setiap orang yang mempunyai kelainan fisik dan/atau mental, yang dapat mengganggu atau merupakan rintangan dan hambatan baginya untuk melakukan secara selayaknya, yang terdiri dari:

1. penyandang cacat fisik;

2. penyandang cacat mental; serta

3. penyandang cacat fisik dan mental.

\section{B. Bahasa Isyarat}

Bahasa isyarat merupakan kaedah komunikasi yang tidak menggunakan suara, tetapi pergerakan tangan, badan dan bibir untuk menyampaikan maklumat dan melahirkan fikiran seorang penutur [6] . Bahasa isyarat berkembang di kalangan komuniti pekak dan tuli, dan juga digunakan oleh suadaramara penutur pekak, serta juru bahasa isyarat. Bahasa isyarat merupakan bahasa yang, tidak menggunakan pola bunyi, sebaliknya menggunakan pola isyarat dihantar (komunikasi manual, bahasa badan) untuk memberi makna-serentak dengan gabungan bentuk tangan, orientasi dan pergerakkan tangan, lengan, atau badan, dan raut muka untuk menggambarkan dengan licin pemikiran penutur.

Bahasa isyarat adalah metode komunikasi untuk orangorang yang tuli atau tuna rungu di mana gerakan tangan, gerakan tubuh dan ekspresi wajah menyampaikan struktur tata bahasa dan makna [7].

Bahasa Isyarat adalah bahasa yang mengutamakan komunikasi manual, bahasa tubuh, dan gerak bibir, bukannya suara, untuk berkomunikasi. Kaum tuna rungu adalah kelompok utama yang menggunakan bahasa ini, biasanya dengan mengkombinasikan bentuk tangan, orientasi dan gerak tangan, lengan, dan tubuh, serta ekspresi wajah untuk mengungkapkan pikiran mereka. Untuk Indonesia, ada dua sistem bahasa isyarat yang berlaku, Bahasa Isyarat Indonesia (BISINDO) dan Sistem Isyarat Bahasa Indonesia (SIBI).

\section{TUNARUNGU/TULI}

Tuli, tunarungu, atau gangguan dengar dalam kedokteran adalah kondisi fisik yang ditandai dengan penurunan atau ketidakmampuan seseorang untuk mendengarkan suara [8].

Tuli dalam kedokteran dibagi atas 3 jenis:

1. Tuli/Gangguan Dengar Konduktif adalah gangguan dengar yang disebabkan kelainan di telinga bagian luar dan/atau telinga bagian tengah, sedangkan saraf pendengarannya masih baik, dapat terjadi pada orang dengan infeksi telinga tengah, infeksi telinga luar atau adanya serumen di liang telinga.

2. Tuli/Gangguan Dengar Saraf atau Sensorineural yaitu gangguan dengar akibat kerusakan saraf pendengaran, meskipun tidak ada gangguan di telinga bagian luar atau tengah.

3. Tuli/Gangguan Dengar Campuran yaitu gangguan yang merupakan campuran kedua jenis gangguan dengar di atas, selain mengalami kelainan di telinga bagian luar dan tengah juga mengalami gangguan pada saraf pendengaran.

Untuk menentukan jenis dan derajat ketulian dapat diperiksa dengan audiometri. Disamping dengan pemeriksaan audiometri, ambang respon seseorang terhadap bunyi dapat juga dilakukan dengan pemeriksaan BERA (Brainstem Evoke Response Audiometry, dapat dilakukan pada pasien yang tidak dapat diajak komunikasi atau anak kecil.

\section{Pengertian Huruf Hijaiyah}

Huruf arab adalah huruf hijaiyah. Huruf hijaiyah adalah kumpulan huruf-huruf arab yang berjumlah 30 huruf. Hurufhuruf inilah yang terpakai dalam Al-Qur'an dan dikenal pada masa sekarang. Sedangkan menurut KBBI hijaiah huruf Arab (dari alif sampai ya) [9].

\section{E. XАMPP}

$X A M P P$ adalah fasilitas untuk banyak sistem operasi seperti Windows, Linux, Mac, dan Solaris yang memungkinkan sebuah web dinamis bisa diakses secara local menggunakan web server local [10]. Kata XAMPP sendiri terdiri dari :

a. X yang berarti Cross Platform karena XAMPP bisa dijalankan di Windows, Linux, Mac, dan Solaris.

b. A yang berarti Apache sebagai web server nya.

c. M yang berarti MySQL sebagai Database Management System (DBMS)

d. PP yang berarti PHP dan Perl sebagai bahasa yang didukungnya.

\section{F. $P H P$}

PHP adalah sebuah bahasa pemrograman web berbasis server (server-side) yang mampu memparsing kode PHP dari kode web dengan ekstensi.php, sehingga menghasilkan tampilan website yang dinamis di sisi client (browser) [11]. PHP adalah bahasa script yang sangat cocok untuk pengembangan web dan dapat dimasukkan ke dalam HTML.

\section{G. $M Y S Q L$}

MySQL merupakan database yang paling digemari di kalangan programmer web, dengan alasan bahwa program ini merupakan database yang sangat kuat dan cukup stabil untuk digunakan sebagai media penyimpanan data. Sebagai sebuah database server yang mampu untuk memanajemen database dengan baik, MySQL terhitung merupakan database yang paling digemari dan paling banyak digunakan dibanding database lainnya" [12].

\section{H. Unified Modeling Language (UML)}

UML (Unified Modeling Language) adalah 'bahasa' pemodelan untuk sistem atau perangkat lunak yang berparadigma 'berorientasi objek' [13]. Pemodelan (modeling) sesungguhnya digunakan untuk penyederhanaan 
permasalahan-permasalahan yang kompleks sedemikian rupa sehingga lebih mudah dipelajari dan dipahami”.

Unified Modeling Language (UML) adalah sebuah standarisasi bahasa pemodelan untuk pembangunan perangkat lunak yang dibangun dengan menggunakan teknik pemrograman berorientasi objek [14]. Ada 3 diagram yang digunakan dalam penelitian ini yaitu class diagram, use case diagram dan activity diagram.

\section{Class Diagram}

class diagram menggambarkan struktur sistem dari segi pendefinisan kelas - kelas yang akan dibuat untuk membangun sistem.

2. Use Case Diagram

use case diagram merupakan pemodelan untuk kelakuan sistem yang dibuat, use case diagram medeskripsikan sebuah interaksi antara satu atau lebih aktor dengan sistem informasi yang akan dibuat.

3. Activity Diagram

activity diagram menggambarkan workflow (aliran kerja) atau aktivitas dari sebuah sistem atau proses bisnis. Diagram aktivitas menggambarkan aktivitas - aktivitas sistem bukan apa yang dilakukan aktor.

\section{METODOLOGI PENELITIAN}

Metode pengembangan sistem yang digunakan dalam penelitian ini yaitu: metode waterfall [15]. Metode air terjun (waterfall) sering juga disebut model sekuensial linier (sequential linear) atau alur hidup klasik (classiclife cycle). Model air terjun menyediakan pendekatan alur hidup terurut mulai darianalisis, desain, pengodean, pengujian, dan pemeliharaan.Tahapan metode air terjun dapat dilihat pada Gambar 1.

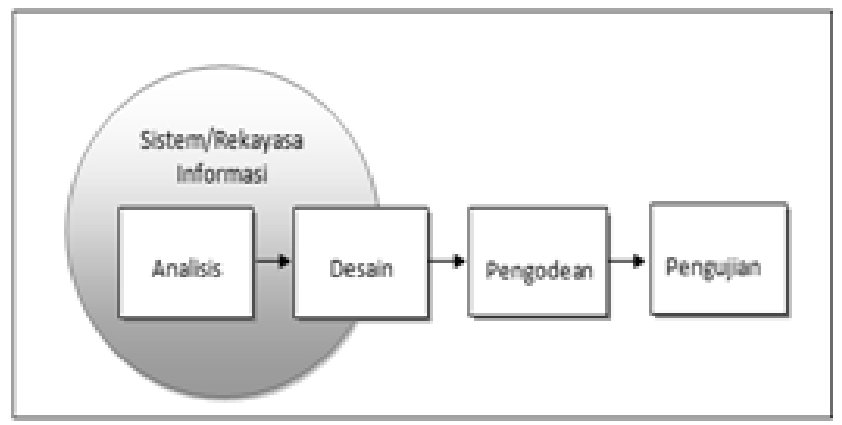

Gambar 1. Metode Waterfall

\section{A. Analisis}

Proses pengumpulam kebutuhan dilakukan secara intensif untuk menspesifikasikan kebutuhan perangkat lunak agar dapat dipahami perangkat lunak sepeti apa yang dibutuhkan oleh user. Spesifikasi kebutuhan perangkat lunak pada tahap ini perlu untuk didokumentasikan.

\section{B. Desain}

Desain perangkat lunak adalah proses multilangkah yang fokus pada desain pembuatan program perangkat lunak termasuk struktur data, arsitektur perangkat lunak, representasi antarmuka, dan prosedur pengodean. Tahap ini mentranslasi kebutuhan perangkat lunak dari tahap analisis kebutuhan ke representasi desain agar dapat diimplementasikan menjadi program pada tahap selanjutnya. Desain perangkat lunak yang dihasilkan pada tahap ini juga perlu didokumentasikan.

\section{Pengkodean}

Desain harus ditranslasikan ke dalam program perangkat lunak. Hasil dari tahap ini adalah program komputer sesuai dengan desain yang telah dibuat pada tahap desain.

\section{Pengujian}

Pengujuan fokus pada perangkat lunak secara dari segi lojik dan fungsional dan memastikan bahwa semua bagian sudah diuji. Hal ini dilakukan untuk meminimalisir kesalahan (error) dan memastikan keuaran yang dihasilkan sesuai dengan yang diinginkan.

\section{E. Pemeliharaan (Maintenance)}

Tidak menutup kemungkinan sebuah perangkat lunak mengalami perubahan ketika sudah dikirimkan ke user. Perubahan itu bisa ada karena adanya kesalahan yang muncul dan tidak terdeteksi saat pengujian atau perangkat lunak harus beradaptasi dengan lingkungan baru. Tahap pendukung atau pemeliharaan dapat mengulangi proses pengembangan mulai dari analisis spesifikasi untuk perubahan perangkat lunak yang sudah ada, tapi tidak untuk membuat perangkat lunak baru.

\section{HASIL DAN PEMBAHASAN}

\section{A. Halaman Menu Utama}

Tampilan menu ini merupakan menu untuk memulai pembelajaran huruf hijaiyah yang dapat dilihat pada Gambar 2 di bawah ini:

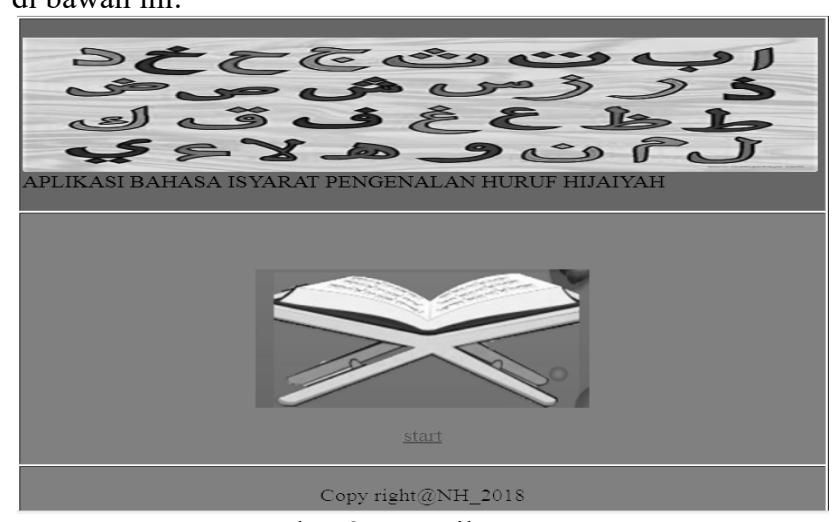

Gambar 2. Tampilan Menu Utama

\section{B. Halaman Menu Mulai Pembelajaran}

Untuk memulai pembelajaran dengan mengklik tombol start. Pada menu ini terdapat huruf-huruf hijaiyah yang terdiri 
dari 29 huruf. Untuk lebih jelasnya dapat dilihat pada Gambar 3 .

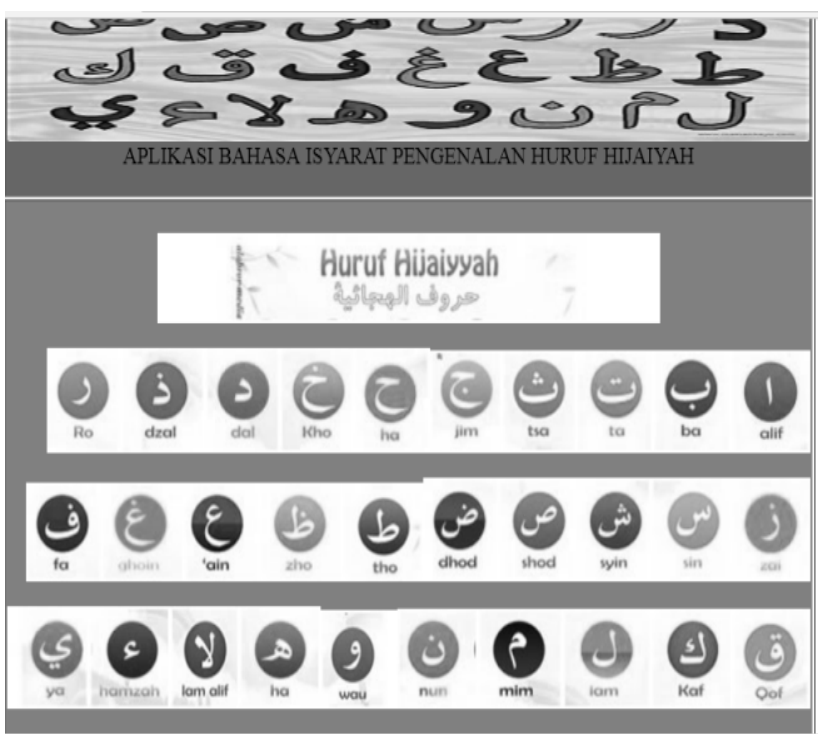

Gambar 3. Tampilan Menu Mulai Pembelajaran

C. Halaman Menu Tampilan Bahasa Isyarat Huruf Alif

Setelah mengklik huruf hijaiyah alif maka akan langsung masuk kemenu huruf hijaiyah alif dalam bahasa isyarat, seperti pada Gambar 4.

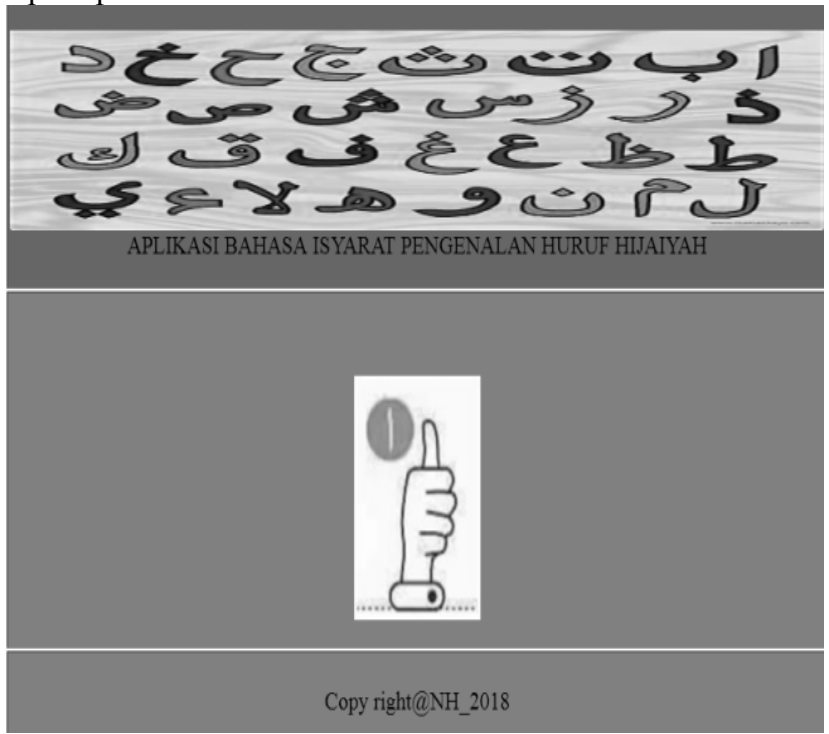

Gambar 4. TampilanBahasa Isyarat Huruf Alif

D. Halaman Menu Tampilan Bahasa Isyarat Huruf Ba

Setelah mengklik huruf hijaiyah Ba maka akan langsung kemenu huruf hijaiyah $\mathrm{Ba}$ dalam bahasa isyarat, seperti pada Gambar 5.

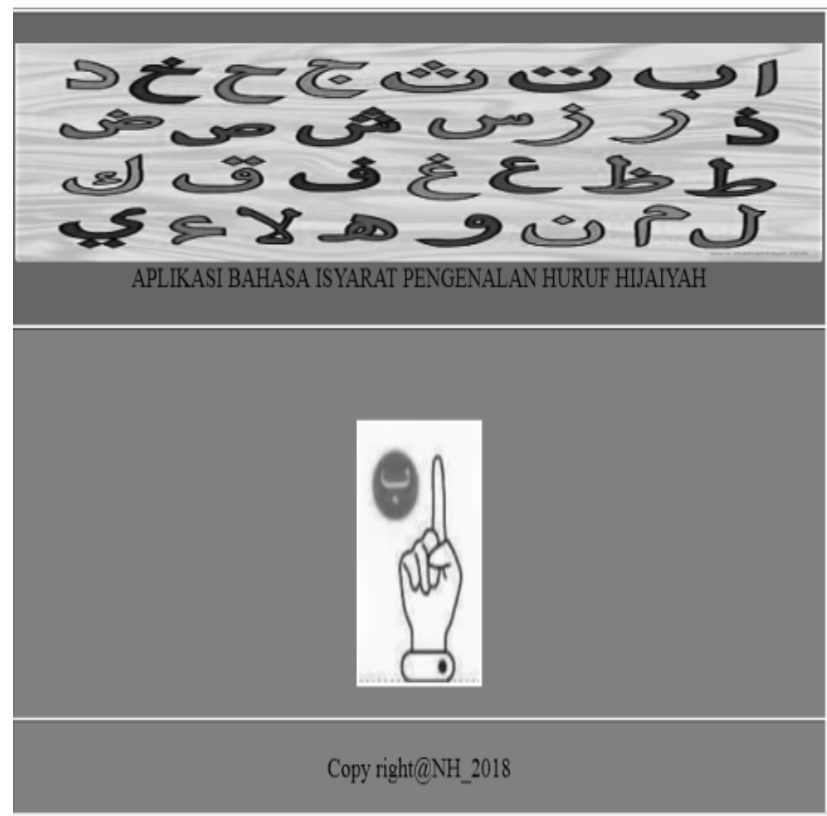

Gambar 5. TampilanBahasa Isyarat Huruf Ba

E. Halaman Menu Bahasa Isyarat Huruf Ta

Setelah mengklik huruf hijaiyah Ta maka akan langsung kemenu huruf hijaiyah Ta dalam bahasa isyarat, seperti pada Gambar 6.

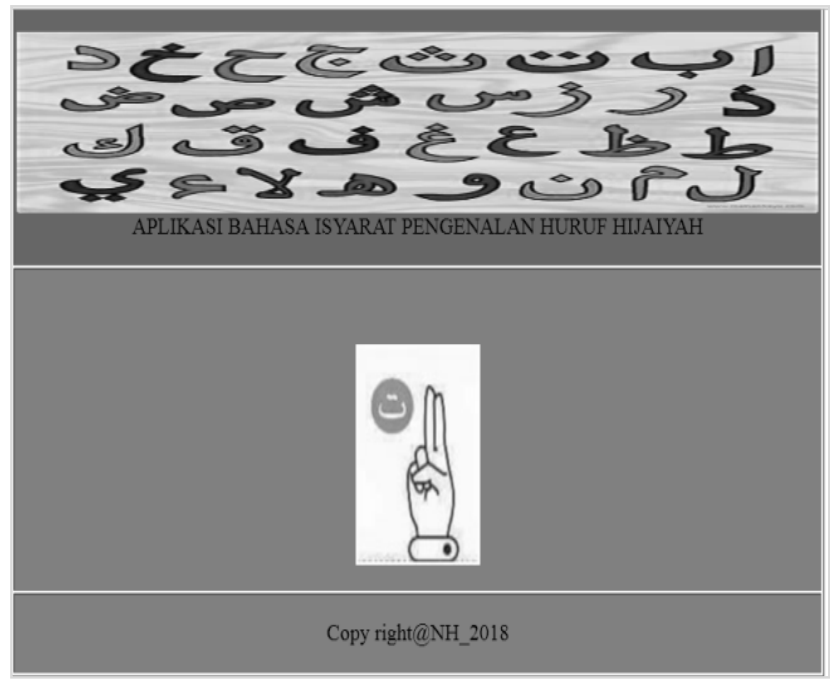

Gambar 6. TampilanBahasa Isyarat Huruf Ta

F. Halaman Menu Tampilan Bahasa Isyarat Huruf Tsa

Setelah mengklik huruf hijaiyah Tsa maka akan langsung kemenu huruf hijaiyah Tsa dalam bahasa isyarat, seperti pada Gambar 7. 


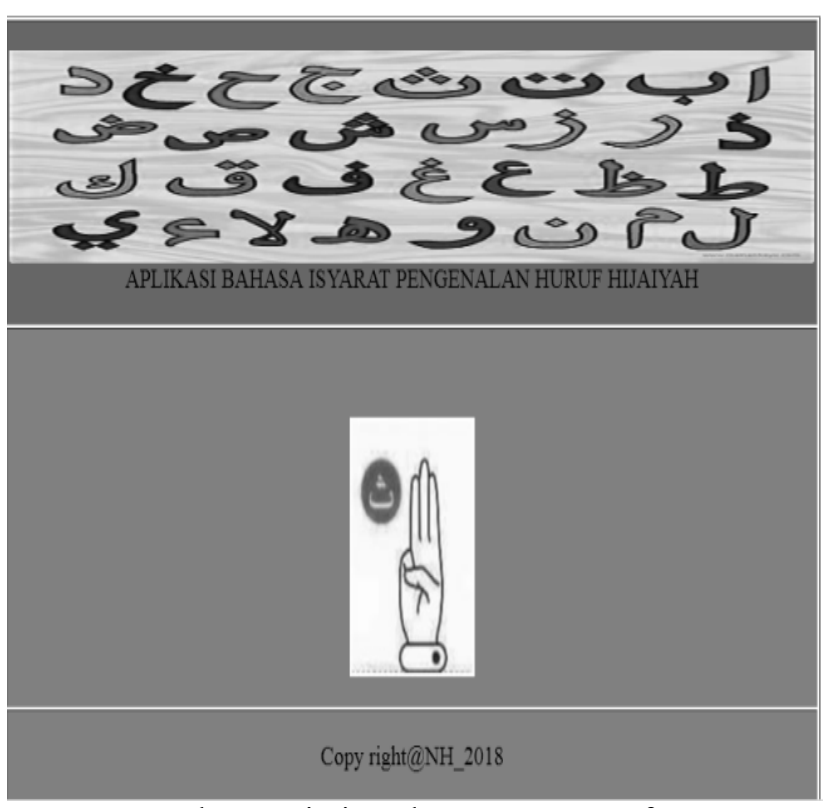

Gambar 7. Disain Bahasa Isyarat Huruf Ta

\section{G. Halaman Menu Bahasa Isyarat Huruf Jim}

Setelah mengklik huruf hijaiyah Jim maka akan langsung kemenu huruf hijaiyah Jim dalam bahasa isyarat, seperti pada Gambar 8.

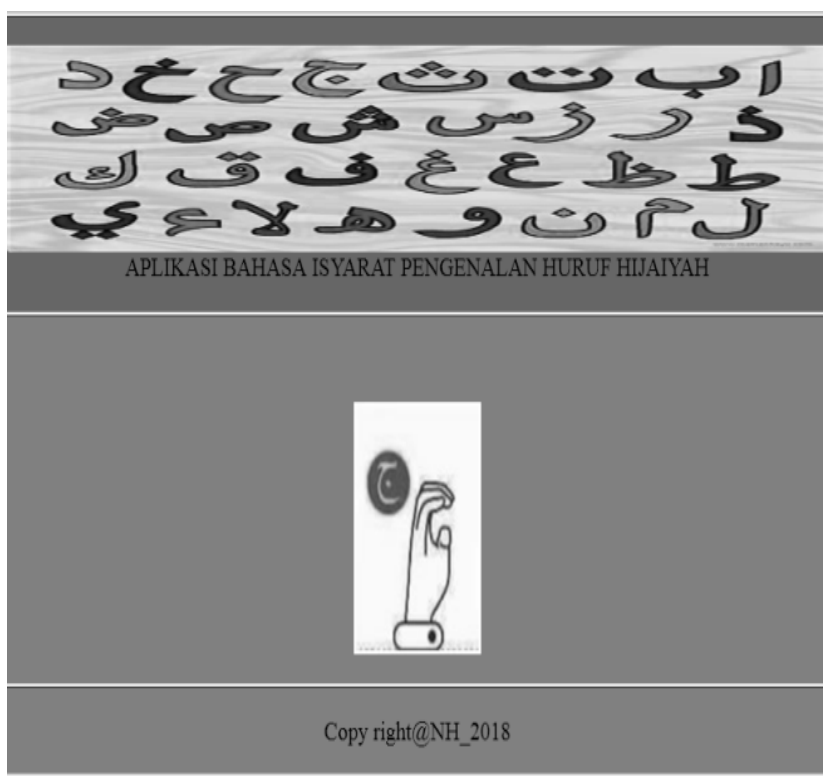

Gambar 8. Disain Bahasa Isyarat Huruf Jim

\section{KESIMPULAN}

Berdasarkan hasil penelitian yang dilakukan maka dapat disimpulkan bahwa aplikasi bahasa isyarat pengenalan huruf hijaiyah bagi penyandang disabilitas tuna rungu ini telah berhasil dibuat dan aplikasi ini dapat membantu mempermudah para penderita tuna rungu dalam mempelajari huruf hijaiyah dan dapat membaca Al-Qur'an dengan baik dan benar. Untuk pengembangan selanjutnya agar dapat dibuat dalam bentuk aplikasi berbasis android dan dapat ditambahkan dalam bentuk gambar multimedia sehingga tampilannya dapat lebih interaktif.

\section{DAFTAR PUSTAKA}

[1] N. Huda and N. A. O. Saputri, "Aplikasi PembelajaranBahasa Isyarat bagi Penyandang Disabilitas Tunarungu Berbasis Desktop," in Prosiding Seminar Nasional Darmajaya, 2018, pp. 19-26.

[2] S. Subandi, I. G. N. Triska, I. M. D. Susila, and I. G. Harsemadi, "Augmented Reality Book STMIK STIKOM Bali Berbasis Android Mobile," JOSINFO J. Online Sist. Inf., vol. 1, no. 1, 2015.

[3] N. M. L. K. Putri, D. P. Parmiti, and I. K. Sudarma, "Pengembangan Video Pembelajaran dengan Bahasa Isyarat Berbasis Pendidikan Karakter pada Siswa Kelas V di SDLB-B Negeri I Buleleng Tahun Pelajaran 2017/2018," J. EDUTECH Undiksha, vol. 8, no. 2, 2017.

[4] A. Rohmawati, "Efektivitas Pembelajaran," JPUDJurnal Pendidik. Usia Dini, vol. 9, no. 1, pp. 15-32, 2015.

[5] S. Thohari, "Pandangan Disabilitas dan Aksesibilitas Fasilitas Publik bagi Penyandang Disabilitas di Kota Malang,” Indones. J. Disabil. Stud., vol. 1, no. 1, 2017.

[6] I. Kautsar, R. I. Borman, and A. Sulistyawati, "Aplikasi Pembelajaran Bahasa Isyarat Bagi Penyandang Tuna Rungu Berbasis Android Dengan Metode BISINDO," in SEMNASTEKNOMEDIA ONLINE, 2015.

[7] R. A. Mursita, "Respon Tunarungu terhadap Penggunaan Sistem Bahasa Isyarat Indonesa (SIBI) dan Bahasa Isyarat Indonesia (Bisindo) dalam Komunikasi,” Inklusi, vol. 2, no. 2, pp. 221-232, 2015.

[8] M. Bangsawan and H. Ilyas, "Analisis Karakteristik Pekerja dengan Gangguan Ketulian Pekerja Pabrik Kelapa Sawit," J. Ilm. Keperawatan Sai Betik, vol. 10, no. 2, pp. 251-257, 2017.

[9] M. E. Apriyani, M. Huda, and S. Prasetyaningsih, "Analisis Penggunaan Marker Tracking Pada Augmented Reality Huruf Hijaiyah," J. Infotel, vol. 8, no. 1, pp. 71-77, 2016.

[10] H. T. Sihotang, "Sistem Informasi Pengagendaan Surat berbasis Web Pada Pengadilan Tinggi Medan," $J$. Inform. Pelita Nusant., vol. 3, no. 1, pp. 6-9, 2018.

[11] M. Suhartanto, "Pembuatan Website Sekolah Menengah Pertama Negeri 3 Delanggu dengan menggunakan PHP dan Mysql," Speed-Sentra Penelit. Eng. dan Edukasi, vol. 4, no. 1, 2017.

[12] H. O. L. Wijaya, "Penerapan Metode Waterfall pada Sistem Informasi Pendaftaran Pasien Rawat Jalan berbasis Web Mobile," J. SISFOKOM, vol. 6, no. 2, pp. 80-85, 2017. 
[13] H. Hartono and J. Jimmy, "Perancangan Aplikasi Mobile Repository Skripsi (Skripsi Alumni Mahasiswa) STMIK IBBI Medan berbasis Android," J. Ilm. Core IT Community Res. Inf. Technol., vol. 5, no. 2, 2017.

[14] A. Anisah and S. Sayuti, "Perancangan Sistem Informasi Registrasi Online untuk Penerimaan Siswa Baru berbasis Web pada SMK Negeri 1 Kelapa Bangka Barat," J. SISFOKOM, vol. 7, no. 2, pp. 174-179, 2018.

[15] T. Sugihartono, D. Ardiansyah, and M. Zakky, "Implementasi Sistem Pendukung Keputusan Penerima Bantuan Rumah Tidak Layak Huni berbasis Web," J. SISFOKOM, vol. 7, no. 1, pp. 52-56, 2018. 